\title{
Acesso negado: circuit bending, borderlands science fiction e lo-fi sci-fi em Branco Sai, Preto Fica
}

\section{Access denied: circuit bending, borderlands narratives and lo-fi sci-fi in White Out, Black in}

\author{
Alfredo Suppia \\ Professor Doutor do Departamento de Cinema (Decine) e do Programa de pós-graduação em Multimeios, Universidade Estadual \\ de Campinas (Unicamp).
}

<alsuppia@gmail.com>

\section{RESUMO}

Branco Sai, Preto Fica (2014), de Adirley Queirós, mescla documentário e ficção científica para discutir a cidadania e os direitos civis sob a alça de mira do estado. Realizado com verba de um edital público destinado à produção de filmes documentários, o filme de Adirley Queirós recorre a toda sorte de circuit bending narrativo, cenográfico e de mise-en-scène no sentido de provocar o estranhamento cognitivo de cenários e situações aparentemente familiares e corriqueiros. Branco Sai, Preto Fica é também um filme fronteiriço, híbrido em termos de gênero e regime de representação, e também sua fábula se situa num território de fronteira. Este trabalho pretende analisar Branco Sai, Preto Fica à luz dos conceitos contemporâneos de circuit bending, borderlands science fiction e lo-fi sci-fi.

Palavras-chave: Cinema. Documentário. Ficção científica.

\begin{abstract}
Adirley Queirós's White Out, Black In (Branco Sai, Preto Fica, 2014) mixes documentary and science fiction film to discuss civil rights and citizenship menaced by the state, Produced with funds originating from a call targeted at documentary filmmaking, the film resorts to all sorts of circuit bending in terms of its narrative, set designs and mise-en-scène, in order to provoke cognitive estrangement out of seemingly familiar and ordinary circumstances and landscapes. White Out, Black In is also a borderlands film, an interesting case of genre chimera whose narrative is set in a frontier area, the one that isolates Brasilia, the federal district, from Ceilândia, a working class city. This work aims to analyze Adirley Queirós's film under the perspective of three contemporary cultural concepts: circuit bending, borderlands science fiction and lo-fi sci-fi.
\end{abstract}

Keywords: Cinema. Documentary. Science fiction.

Introdução: circuit bending

"Aqui é o lugar onde o espaço mais se parece com o tempo." Clarice Lispector sobre Brasília (In: Xavier e Katinsky [orgs.] 2012, p. 182).

Branco Sai, Preto Fica (2014), de Adirley Queirós, mescla documentário e ficção científica para discutir a cidadania e os direitos civis sob a alça de mira do estado. Vencedor do Festival de Brasília de 2014, este longa-metragem recorre 
ao artifício da viagem no tempo para tratar de um fato real ocorrido na noite de 5 de março de 1986, quando policiais invadiram o Quarentão, baile de black music organizado na periferia da capital federal, para agredir violentamente os jovens frequentadores do evento. $\mathrm{O}$ título do filme remete à ordem de um dos policiais agressores, o qual teria ordenado que os jovens negros permanecessem no recinto do baile. Conforme explicado por Adirley Queirós enquanto o projeto ainda estava em fase de produção:

O nome do filme é "Branco sai e preto fica". Porque em várias das narrativas dizem que os caras da polícia chegaram e falaram assim: "quem for branco pode sair, aqui é um baile black". Um me falou assim: "um cara chegou e falou assim: 'ó, branco sai e preto fica' - aí como não tinha branco, ele colocou todo mundo deitado no chão". Isso é outra coisa recorrente: que eles colocaram a cavalaria para pisar em cima dos caras. Imagina a opressão cabulosa que não foi aquilo! Eles batem nos caras, põem as mulheres na parede, dão chute na bunda, bolacha, telefone... Então existiu ali um processo de humilhação muito grande. O filme vai ser todo filmado como se fosse uma ficção científica, vai ter o depoimento desses caras, todos eles no estúdio com a luz igual tipo o Ônibus 174 (José Padilha, 2002) - vocês se lembram? E vai ter um cara que vai ser o narrador da história, que é um detetive. A gente não sabe o que esse cara quer. $\mathrm{E}$ a brincadeira do detetive é que ele consegue ter uma passagem pelo tempo. $\mathrm{O}$ filme todo vai ser filmado numa onda fotográfica de ficção científica... (Reis, Mena e Imanishi, 2013, p. 66).

Realizado com verba de um edital para filme documentário, Branco Sai, Preto Fica (BSPF) consistiu num projeto ambicioso de "insubordinação" ou circuit bending, não só das políticas de fomento para o audiovisual no Brasil, como também das formas narrativas mais estatutárias no que se refere à representação cinematográfica de fatos reais, além da própria relação do cinema brasileiro com o filme de gênero, em especial o filme de ficção científica. A propósito, o conceito e a prática do circuit bending, familiar à arte eletrônica ou à arte contemporânea, parece especialmente útil à decifração do filme de Adirley Queirós.

Circuit bending corresponde à prática de modificar peças eletrônicas, eventualmente brinquedos, para criar outros itens, geralmente instrumentos musicais. O termo nasceu no contexto da arte sonora, da criação de novos instrumentos musicais, sobretudo eletrônicos. A prática se expandiu e começou a atrair um número cada vez maior de simpatizantes, provavelmente a partir da grande disponibilidade de brinquedos eletrônicos, gadgets e outros materiais 
cotidianamente descartados. Em abril de 2004, Nova York acolheu o Bent, o primeiro festival especialmente dedicado ao circuit bending. Mas o conceito não é totalmente recente. Reed Ghazala, conhecido como o pai do circuit bending, concebeu a prática no final dos anos 1960 quando, ainda adolescente, inspirouse pelos estranhos ruídos emitidos por um pequeno amplificador a bateria'. Expandindo-se o conceito para além do campo musical, é possível definir o circuit bending como qualquer prática de "ressignificação" ou, melhor dizendo, "repropositura" de um dado objeto, instrumento ou dispositivo, musical ou não. Uma das hipóteses deste trabalho é a de que a idéia de circuit bending perpassa $B S P F$ nos mais diversos níveis - desde sua própria viabilização enquanto projeto cinematográfico, passando por sua cenografia, mise-en-scène etc.

Para uma compreensão mais ampla de BSPF, convém levarmos em consideração o contexto de produção do filme, bem como um pouco da biografia de seu realizador. BSPF foi produzido no âmbito do Ceicine, a Cooperativa de Cinema em Ceilândia², e dirigido por um cineasta cujo perfil destoa da tradição em termos de biografia do típico diretor brasileiro, oriundo da classe média, classe média alta e mesmo elite do país. Ex-jogador de divisões de base do futebol no centro-oeste brasileiro e morador da periferia de Brasília, Adirley Queirós só teve acesso à formação universitária perto dos 30 anos, quando começou a frequentar o curso de cinema da Universidade de Brasília (UnB), depois de ter concluído tardiamente o ensino médio e passado por uma série de experiências profissionais tipicamente proletárias. Queirós se define como um cineasta radicalmente independente e popular (Cf. Reis et al., 2013; Suppia e Gomes, 2016).

Em BSPF, o distanciamento de uma ficção científica supostamente mais "modelar", a superposição de regimes narrativos e a peculiaridade do personagem do viajante do tempo talvez possam ser melhor compreendidos se atentarmos para o processo criativo de Adirley Queirós, o qual tem admitido repetidas vezes que não trabalha com roteiro, pelo menos não com o roteiro tradicional do filme de ficção (Cf. Reis, Mena e Imanishi, 2013, p. 24, além de entrevista concedida a este autor, gravada em vídeo ${ }^{3}$ ). Segundo o cineasta, suas narrativas acontecem mesmo na montagem (Cf. Reis, Mena e Imanishi, 2013, p. 26).

A exemplo do curta Barbosa (Jorge Furtado, 1988), BSPF parece confirmar uma certa "especialidade" do cinema nacional mais afeito à narrativa fantástica

1 Ver: http://whatis.techtarget.com/definition/circuit-bending.

2 Ver: http://ceicinecoletivodecinema.blogspot.com.br/.

3 Disponível em <https://www.youtube.com/watch?v=7t64uDP2rPo > 
ou especulativa: a aventura de viagem no tempo que revisita algum trauma na história brasileira. Assim como em Barbosa - que versa sobre a histórica derrota do Brasil para o Uruguai na Copa do Mundo de 1950, evento protagonizado pelo goleiro da seleção brasileira que dá nome ao curta -, personagens reais participam da reconstituição ficcional dos fatos no longa de Queirós. Ofilme inicia com um prólogo, no qual o personagem do radialista Marquim (interpretado por Marquim do Tropa, da banda de rap Tropa de Elite), reconta em monólogo o trágico incidente do Quarentão.

$B S P F$ é ambientado num futuro próximo indeterminado em que a segregação centro-periferia persiste e se intensifica. As populações periféricas são excluídas da capital, notícias de rádio e toques de recolher sugerem um estado policial racista e um regime de restrição das liberdades civis, numa distopia que ratifica definitivamente a previsão de Mário Pedrosa sobre o destino da capital federal: "[...] um oásis, com seu clima e atmosfera inevitáveis de exceção" (2012, p. 43). "Por receio de que a nova capital seja invadida por multidões de negros famintos, faz-se severo controle da migração interna" (Zevi, 2012, p. 67) ${ }^{4}$, e o trânsito de pessoas no plano piloto de Brasília só é permitido mediante apresentação de passaportes. Nesse contexto vivem dois personagens "reais": o radialista Marquim (Marquim do Tropa), e o mecânico de próteses Sartana (Cláudio Irineu Shokito). Esses dois personagens, que na verdade se confundem com os atores, sobreviveram à noite de violência policial no Quarentão, trazendo em seus corpos a marca da agressão. Marquim ficou paraplégico após levar, indefeso, um tiro da polícia. Sartana/Shokito perdeu uma perna depois de ser pisoteado pela cavalaria. Os depoimentos de Marquim do Tropa e Shokito são costurados a cenas ficcionais em que seus respectivos personagens conduzem um plano de vingança. Nesse futuro alternativo de Ceilândia, os sobreviventes Marquim e Sartana vão explodir Brasília com uma "bomba sonora", um artefato apocalíptico que inclui variedades da música popular de periferia. Paralelamente a isso, um viajante do tempo, Dimas Cravalanças (Dilmar Durães), é enviado do ano de 2070 para investigar o caso do baile do Quarentão de Ceilândia. A máquina do tempo de Dimas é um simples contêiner e, assim como em La Jettée (1962), de Chris Marker, ou Je t'Aime, Je t’Aime (1968), de Alain Resnais,

4 Esta citação foi aqui inserida com propósito irônico pois, embora seja absolutamente pertinente à descrição do universo ficcional de BSPF, nada tem a ver com o filme. Trata-se de uma observação feita por Bruno Zevi, originalmente na revista L'Architettura - Cronache e Storia, n. 51, Milão, jan. 1960, p. 608619, texto reproduzido em Xavier e Katinsky (2012), p. 66-72. Haja vista o fato de ser trecho de uma crítica arquitetônica de Brasília publicada já em 1960, a observação parece reveladora da extrapolação moderada no universo ficcional de BSPF, filme que se pretende ficção científica, mas que, para o bem ou para o mal, parece substancialmente "colado" à realidade sobre a qual fabula. 
nenhuma explicação sobre tecnologia é necessária para justificar a viagem no tempo. No caso do filme brasileiro, ao invés da cura de uma epidemia ou um caso de amor perdido, o viajante do tempo tem como missão "achar o paradeiro de Sartana, a chave para incriminar o estado brasileiro por crimes praticados contra populações periféricas", e assim alimentar de provas o processo judicial 095000666/2070.

No primeiro terço do filme, enquanto o viajante do tempochega à Ceilândia (ainda mais) distópica de um futuro próximo, depoimentos em voz over dos personagens Marquim e Sartana vão recontextualizando a noite de violência no baile do Quarentão. Após mais de três anos em missão e praticamente dado como perdido por seus chefes no futuro, Dimas Cravalanças finalmente localiza o paradeiro de Sartana, porém não chega a fazer contato com ele. Sartana, por sua vez, parece sentir a presença do viajante do tempo nos arredores de sua casa.

Pouco depois, Marquim negocia com seu amigo Jamaika (DJ Jamaika) o fornecimento de dois passaportes para entrada no plano piloto, em troca de ajuda com as gravações e mixagens de sons e canções genuinamente populares. As gravações servem para alimentar a "bomba sonora" que Marquim vem construindo noite após noite.

No terço final da narrativa, Dimas assiste, no interior de sua "máquina do tempo" (o contêiner), aos depoimentos gravados de Sartana e Marquim. A cena indica que, a esta altura, Dimas conclui sua missão de coletar provas dos crimes do estado brasileiro contra a população negra e pobre. Em paralelo, Sartana e Marquim acabam então reunidos para os ajustes finais da "bomba sonora" e o acerto dos detalhes de seu plano de ataque à capital federal.

Finalmente Marquim detona a "bomba sonora", cuja "massa" de falas, ruídos e melodias da periferia vai devastar o plano piloto. "Bomba explode na cabeça / Estraçalha ladrão...", é o refrão de uma das canções mixadas no artefato. O congresso nacional é um dos primeiros alvos da bomba, em cenas agora representadas pelo traço de Sartana/Shokito.

\section{Tupinipunk, ficção científica do sul e o basurapunk}

A cenografia e a direção de arte em BSPF parecem evocativos de um "cinema de ficção científica do sul" (ver Lim, 2016), como Sleep Dealer (Alex Rivera, 2008), ou Distrito 9 (District 9, Neill Blomkamp, 2009). Trata-se de um cyberpunk do Terceiro Mundo, do hemisfério sul ou, ainda, no caso de narrativas brasileiras de ficção científica, de um "tupinipunk" - nos termos do crítico e escritor Roberto de Sousa Causo. Cunhado por Causo (1996) e difundido por 
autores internacionais como Mary Elizabeth Ginway, o tupinipunk corresponde a um estilo inspirado no Modernismo e no Tropicalismo brasileiros, repleto de referências antropofágicas de jocosidade e iconoclastia marcadamente brasileiras (Causo, 2015, p. 11). Causo explica que

Inicialmente o tupinipunk [cyberpunk tupiniquim] foi um fenômeno característico das décadas de 1980 e 90 . Basta conferir a parte inicial do corpus existente: Silicone XXI (1985), romance de Alfredo Sirkis; contos de Braulio Tavares como "Stuntmind" e "Jogo Rápido" (1989); novelas como Santa Clara Poltergeist (1991), de Fausto Fawcett, e Piritas Siderais: Romance Cyberbarroco (1994), de Guilherme Kujawski; os contos e noveletas de Fawcett no seu segundo livro, Básico Instinto (1992); e os contos "Ananda, o Homem que Purpurava" e "O Caipira Caipora" (1993), de Ivan Carlos Regina - além do seu importante "Manifesto Antropofágico da Ficção Científica Brasileira" (1988). E finalmente, "O Altar dos nossos Corações" (1993), excepcional noveleta de Ivanir Calado (Causo, 2015, p. 11).

Enquanto cyberpunk do sul ou tupinipunk, BSPF parece apostar no estranhamento de situações e paisagens aparentemente ordinárias, como quando o "ciborgue" Sartana atravessa um terreno baldio para chegar à oficina de um "hacker" . Lá sua perna mecânica é conectada a um computador e tem sua "senha" "hackeada". Em seguida, Sartana é "escaneado" pelo computador e pode, a partir de então, usar o"sistema" para configurar sua prótese. Vale lembrar também que o estranhamento levado a cabo em BSPF apenas agudiza uma sensação a priori identificada com a capital federal, ampla e frequentemente relatada por personalidades que já visitaram Brasília, como Clarice Lispector ou Yuri Gagarin. Para a escritora brasileira, Lúcio Costa e Oscar Nimeyer não teriam

5 A ideia de "estranhamento cognitivo" (Suvin 1979) a partir de situações e paisagens aparentemente corriqueiras é na verdade controversa, e aqui exposta de modo provisório. Em outra ocasião, e com o devido tempo, pretendemos investigar sobre até que ponto o "estranhamento" ou a impressão de ficção científica, eventualmente provocados por cenas como a descrita acima (envolvendo Sartana), não dizem mais respeito a circunstâncias de recepção do que a características imanentes ao filme. É bem possível que a suposta "aura" de ficção científica, das cenas em que Sartana manipula próteses ou sua própria perna mecânica, seja muito mais fruto da percepção de um(a) espectador(a) de classe média, não-deficiente físico e morador de regiões urbanas mais centrais, do que propriamente de um personagem que utiliza, em seu dia-a-dia, uma prótese para se locomover. A imagem de um personagem que se desloca por paisagens degradadas, com o auxílio de uma perna mecânica, parece distópica em si mesma - mas é muito razoável que não o seja, e que de fato sua dimensão distópica só venha a ser acentuada, num filme como $B S P F$, em função do contexto e repertório de seu público espectador. 
pensado em construir uma cidade bela; "eles ergueram o espanto deles, e deixaram o espanto inexplicado" (Lispector, 2012, p. 180). O cosmonauta russo, por sua vez, segundo lembra Mara Bergamaschi, "[...] não reconheceu Brasília como território humano. 'A ideia que tenho é que estou desembarcando num planeta diferente, que não a terra', definiria, daquela vez" (Bergamaschi, 2010, p. 27). Em linhas gerais, a capital evoca uma sensação de "ficção científica" per se, metaforizada no "Flash Gordon” de Clarice Lispector:

- Nunca vi nada igual no mundo. Mas reconheço esta cidade no mais fundo de meu sonho. O mais fundo de meu sonho é uma lucidez. Pois como eu ia dizendo, Flash Gordon... - Se tirasse meu retrato em pé em Brasília, quando revelassem a fotografia só sairia a paisagem (Lispector, 2012, p. 181).

Sobreposto ao pano de fundo da paisagem da periferia brasiliense, o ciborgue Sartana sugere uma dupla leitura enquanto corpo-personagem, metáfora do estranhamento generalizado eventualmente apreensível em Brasília e de uma distopia futurista baseada no drama da segregação e luta de classes. Com alguma frequência Sartana é enquadrado sozinho, contemplando o horizonte, em planos evocativos da solidão e anonimato relatados por observadores de Brasília, entre eles Clarice Lispector: "- Quando morri, um dia abri os olhos e era Brasília. Eu estava sozinha no mundo" (2012, p. 180). Também Marquim é frequentemente enquadrado só, e a certa altura relata sua sensação após o tiro da polícia que atingiu suas costas: "será que eu morri?" Ainda segundo Clarice Lispector, "Brasília é construída na linha do horizonte. - Brasília é artificial. Tão artificial como devia ter sido o mundo quando foi criado" (2012, p. 179). Artificial também como a perna mecânica de Sartana, a marca de sua integração à história nefasta da cidade. Embora caminhe com desenvoltura, num dado momento Sartana/Shokito relata as provações pelas quais passou quando jovem, em seguida à amputação de sua perna, quando o sonho de jogar futebol, entre outras coisas, foi-lhe arrancado à força pela tirania do estado. A caminhada de Sartana, hoje viabilizada pela prótese, funciona também como metáfora da artificialidade das políticas de segregação e trânsito, bem como da tirania infligida ao corpo de quem não ascede de fato, por razões sócioeconômicas ou raciais, à categoria de cidadão.

Talvez devido à incorporação de uma atmosfera marcadamente "terceiromundista", a estética tupinipunk de um filme como BSPF acentua a 
atmosfera de decadência de filmes cyberpunk avant la lettre - como No Ano de 2020 (Soylent Green, Richard Fleischer, 1979), ou Blade Runner (Ridley Scott, $1982)^{6}$. Contemporaneamente, a reapropriação subsequente da iconografia presente nesses filmes resulta em cenários ainda mais decadentes e poluídos, culminando numa estética que poderíamos chamar provisoriamente de basurapunk - na qual às populações periféricas, geralmente de origem latina, não resta alternativa senão o uso do lixo como tecnologia, num contexto marcadamente pós-colonial. O estilo, se é que podemos chamá-lo assim, já foi cooptado pelo cinema hollywoodiano, como no caso de Elysium (2013), de Neill Blomkamp. BSPF parece também representativo dessa estética que aguça as discrepâncias, sublinha a segregação e preconiza a reapropriação do lixo tecnológico ou dos resíduos industriais como commodities numa estratégia de desobediência civil - culminando no basurapunk aqui sugerido. A estratégia não é nova e tem antecedentes mais amplos, como no famoso desfile da escola de samba Beija-Flor em 1989, com o samba-enredo "Ratos e urubus, larguem a minha fantasia". Sob o comando do carnavalesco Joãosinho Trinta, naquele ano a escola do Rio de Janeiro recorreu ao lixo como tema e estética em sua mobilização da "tecnologia" carnavalesca, num dos mais polêmicos espetáculos da história do carnaval carioca.

Em resumo, a julgar pela performance de alguns de seus personagens, bem como pela releitura das ruínas (ruínas dos corpos violentados pelo estado e das periferias das cidades) e do lixo (tecnológico ou não), BSPF parece evocativo também do barroco, barroco este já observado por Alberto Moravia em seu depoimento acerca de Brasília. Segundo Moravia, já em 1960, Brasília oferecia "[...] uma explosão barroca mascarada de funcionalismo" (2012, p. 92). Seria então $B S P F$, tanto em níveis diegético quanto extra-diegético, tanto em termos de banda sonora quanto de imagem, um filme barroco - como a Brasília de Moravia?

\section{Fronteiras}

Em $B S P F$, a idéia do viajante do tempo que deve coletar provas de um crime para um processo judicial futuro é provocativa pelas seguintes razões. Em primeiro lugar, diferente de outras narrativas do gênero, nas quais o protagonista precisa agir no sentido de restaurar a ordem no passado, presente ou futuro, 0 viajante do tempo de BSPF parece repetir um aspecto já observado por Roberto

$6 \quad$ Aliás, exemplo de um filme tupinipunk avant la lettre talvez possa ser encontrado no brasileiro Parada 88: O Limite de Alerta (José de Anchieta, 1978), produção ainda anterior aos filmes americanos proto-cyberpunk supracitados. 
de Sousa Causo em seu exame da literatura pioneira de ficção científica no Brasil: o fato de os personagens quase sempre serem observadores passivos que pouco ou nada poder têm sobre o curso da história (2003, p. 145). Segundo Causo, a despeito do florescimento inicial das ciências naturais e humanas em fins do século XVIII e começo do XIX no Brasil, o desenvolvimento irregular da ciência e tecnologia no período subsequente acabou soterrado pela necessidade de ordem política e jurídica, fator que teria favorecido a escalada das letras e do direito como disciplinas preponderantes. Amparado no Antonio Cândido de Literatura e Sociedade (2000), Causo defende que

[...] o espírito da burguesia brasileira se desenvolveu sob influxos dominantemente literários, e a sua maneira de interpretar o mundo circundante foi estilizada em termos, não de ciência, filosofia ou técnica, mas de literatura. Se esse contexto responde pela fraca exploração da ciência e tecnologia, em comparação com o scientific romance inglês, francês (verniano) e norte-americano, a ausência da aventura, outro componente fundamental do gênero (romance, em inglês, é traduzido como romanesco, aventuresco, extraordinário), é respondida pela imobilidade social própria do mesmo aspecto colonial que determinou a ausência de instituições e do pensamento científico no Brasil. Imobilidade social e a ausência de perspectivas imediatas de mudança, mudança em geral promovida pela consciência do avanço científico e técnico. O Brasil do século XIX e início do XX era uma nação espectadora, e não agente, nesse processo. E aventura pressupõe ação, a presença de agentes que se posicionam na linha de frente [às vezes como realizadores, outras como repressores] da mudança. Nesse sentido, o elemento romanesco de Wells foi bem menos incorporado que os elementos discursivos, retóricos. Não há Viajante do Tempo, mas espectadores, nos primeiros scientific romances brasileiros. Simultaneamente, a ênfase em aspectos sentimentais sobre os aventurescos estava em concordância com os gostos da época, estabelecidos pelo romancefolhetim, e que certamente se encontravam mais próximos da imobilidade da burguesia brasileira de então (Causo, 2003, p. 145, grifos no original).

Narrativamente, BSPF se distribui superpondo três tempos que nunca se "tocam": o passado (o Quarentão nos anos 1980), o presente (um futuro próximo em relação ao ano de lançamento do filme, 2014) e um futuro distante (final do século XXI, local de origem do viajante do tempo). Dimas Cravalanças não viaja no tempo para mudar a história desfazendo a injustiça (tentativa malograda do protagonista de Barbosa), mas para coletar provas para um 
processo judicial futuro. As provas não são especificadas pela narrativa e o passado injusto está consumado, resta apenas atribuir a responsabilidade um avanço no contexto de uma sociedade com "memória curta", implacável com os pobres e que historicamente não pune crimes de colarinho branco ou abusos do estado. Não por acaso, ao praguejar contra eventuais opressores, enquanto simula atirar contra inimigos num pátio abandonado, Cravalanças o faz num espaço vazio. Mesmo no caso de Barbosa - em que o viajante do tempo pretende alertar o goleiro da seleção brasileira na Copa de 1950, para com isso "corrigir" o passado - o fracasso é inexorável. Como se, diferente do viajante do tempo de culturas protestantes, ao equivalente brasileiro não fosse permitida nenhuma ação verdadeiramente transformadora. Sintoma de uma carência generalizada de agência (no sentido de ato transformador) que pode explicar, em alguma medida, a dificuldade enfrentada pela sociedade brasileira em apurar fatos e atribuir responsabilidades. Seja um deslizamento de terra num bairro de periferia que resulta na morte de cidadãos, o incêndio de uma boate, o desvio de dinheiro público, o naufrágio de uma embarcação ou um acidente aéreo, em qualquer um desses eventos é muito difícil para a sociedade brasileira identificar responsáveis ou culpados - e finalmente puni-los. A nação se confunde com uma massa de espectadores impassíveis diante das peripécias de um Deus caprichoso. Tudo é tratado, em princípio, como fatalidade?.

Em segundo lugar, o próprio fato de o viajante do tempo de BSPF estar em missão de coleta de provas para um processo judicial futuro parece irônico em si mesmo - dado o conhecimento empírico do espectador brasileiro contemporâneo acerca da justiça no país, em especial a justiça que envolve o julgamento de poderosos ${ }^{8}$. Oportunamente, o filme termina antes de qualquer menção aos desdobramentos desse processo judicial futuro - ainda que, em seu último contato com Dimas, o comando da missão tenha dito ao viajante do tempo que "o governo brasileiro será acionado na justiça e as famílias serão ressarcidas". Por outro lado, são os sobreviventes do Quarentão que tomam as

7 Busque-se nos anais da história brasileira recente quais foram os responsáveis e, mais difícil ainda, quais foram os culpados por eventos como o incêndio da boate Kiss em Santa Maria-RS (processo em andamento), o naufrágio do Bateau Mouche IV, na costa do Rio de Janeiro, no Réveillon de 1988 (caso encerrado), os escândalos envolvendo instituições financeiras como o Banco Econômico, o Banco Santos ou o Banco Pactual, o acidente com o avião da TAM no aeroporto de Congonhas, em São Paulo, em 17 de julho de 2017 (caso encerrado com absolvição de todos os acusados), escândalos de corrupção como o do "Mensalão", ou das privatizações sob governos do PSDB, etc., etc., etc...

8 O caso recente da Operação Lava-Jato, conduzida pela Polícia Federal, parece contradizer a "tradição" resumidamente exposta acima, acenando com uma mudança de paradigma - muito embora seja ainda muito cedo para se avaliar uma eventual transformação de fato na longeva história da impunidade no Brasil. 
rédeas da ação, no terço final do filme, e ao que tudo indica são bem-sucedidos em seu plano de explodir a capital federal, mudando o curso da história. Narrada a partir de desenhos, a sequência do ataque terrorista a Brasília nos remete novamente a uma tendência no cinema de ficção científica mais contemporâneo. Antigamente, apenas grandes centros políticos como Londres, Washington, Nova York, Tóquio ou Paris pareciam alvos dignos do apocalipse. Ultimamente, cidades como Johannesburg, Rio de Janeiro e Montevidéu começam a disputar a atenção de alienígenas e artefatos nucleares, no contexto de um "cinema de ficção científica do sul" (nos termos do cineasta Alex Rivera, em Lim, 2016) que resgata a existência da maioria da população mundial, habitante de países subdesenvolvidos ou em desenvolvimento (BRICs incluídos). Adirley Queirós dá sua própria versão acerca dessa reconfiguração dos espaços audiovisuais:

[...] quando eu digo que criei um "personagem Ceilândia" é porque isso também era uma forma de me contrapor aos caras: eles falavam de Nova York e eu falava de Ceilândia. O território é muito forte nesse sentido: como uma construção que nasce da minha experiência. Porque é um imaginário que eu domino (Reis, Mena e Imanishi, 2013, p. 29).

Em que pese a relevância do território para o cinema de Adirley Queirós, BSPF é ilustrativo, no Brasil, da recorrência do filme de fronteira. Referimo-nos a filmes de ficção científica ambientados em regiões de fronteira, tais como $L a$ Sonámbula (Fernando Spiner, 1998), Código 46 (Code 46, Michael Winterbottom, 2003), Filhos da Esperança (Children of Men, Alfonso Cuarón, 2006), ou Sleep Dealer (Alex Rivera, 2008). Alguns desse filmes são também road movies (casos de La Sonámbula ou Filhos da Esperança), e em todos eles parece emergir uma discussão forte a respeito dos colapsos identitários e dos direitos humanos na esteira de um capitalismo cognitivo globalizado, acentuadamente financeiro e informatizado. Nossa hipótese é a de que esses borderlands science fiction films (filmes de ficção científica de fronteira) têm oferecido, ao longo dos últimos anos, uma "moldura" narrativa e uma "paleta de cores" bastante úteis à representação e problematização de temas da agenda contemporânea, notadamente o recrudescimento dos nacionalismos, a xenofobia, o acirramento do estado policial, os rearranjos em termos de fluxos migratórios internacionais e a convivência multiétnica ou multicultural. Também faz parte desta hipótese a suspeita de que, com sua ficção especulativa ambientada em geografias limítrofes ou transicionais, os filmes de ficção científica de fronteira têm recorrido 
com frequência, direta ou indiretamente, à estética documentária e preceitos marxistas em sua problematização do futuro próximo. Conforme exposto pelo cineasta Alex Rivera em entrevista a Crossed Genres:

Quando falamos sobre fantasias, estamos falando sobre realidade. [...] Tenho tido interesse na ideia de narrativas transfronteiriças [trans-border narratives] e fantasia porque sei que vivemos em uma realidade fundamentalmente transfronteiriça. [...] Assim, para mim contar histórias ou usar o gênero da ficção científica para enxergar o fato de que estamos todos conectados através das fronteiras é um trabalho crucial. [...] Para mim, a perspectiva transnacional é o único meio de entender o mundo em que vivemos (2012).

BSPF parece somar-se à tendência ilustrada pelos demais títulos supracitados, sendo um filme de ficção científica de fronteira em variados níveis e por vários motivos. Em primeiro lugar, por seu próprio enredo ou universo diegético: os personagens de BSPF viajam no tempo, transpondo fronteiras cronológicas, ou transitam pela sinistra geografia urbana de uma Brasília futura que segrega acintosamente sua periferia. A situação é claramente ilustrada numa das sequências em que Marquim dirige seu carro adaptado para deficientes físicos em direção ao plano piloto, ouvindo notícias no rádio. A fronteira geográfica ou urbana (centro/periferia) se amplifica e acaba coberta pela fronteira simbólica da segregação (negros/brancos, cidadãos/estrangeiros), a fronteira social. Se um filme como Nosso Lar (2010), de Wagner de Assis, projeta Brasília num plano espiritual de solidariedade e convívio, sugerindo uma cidade fictícia obviamente inspirada no modernismo da capital federal, BSPF escancara "o outro lado da moeda", a faceta distópica da utopia em sua verdade material. A exemplo de distopias futuristas como Metropolis (1927), de Fritz Lang, ou Elysium, BSPF retoma o tema da segregação violenta e luta de classes, apenas transferindo a orientação do eixo hierárquico - de vertical para horizontal, como em Distrito 9 (District 9, 2009), de Neill Blomkamp. A distopia de $B S P F$, no entanto, extrapola muito pouco e sutilmente a realidade urbana do Distrito Federal, conforme pode ser verificado em diagnóstico de David E. Snyder acerca do planejamento urbano da capital, publicado já em 1964:

A diferenciação sociorregional inclui: 1) cidades-satélites como locais de moradia para as classes trabalhadoras; 2) superquadras com prédios de apartamentos, no âmbito da cidade formal, para os 
escalões "médios e baixos" do funcionalismo e das empresas privadas; e 3) bairros residenciais à beira do lago para a elite. É mais do que óbvio, portanto, que o plano "fechado" acabou sendo, neste aspecto crucial, "escancarado". A tentativa deliberada de atenuar as diferenças de classe foi rejeitada (Snyder, 2012, p. 124).

A segregação real, extrapolada sutilmente em BSPF, deve ser problematizada na chave do subdesenvolvimento persistente no país, e nisso convém retomarmos Milton Santos em sua constatação de "duas" Brasílias, já em 1964:

O subdesenvolvimento comparece como um elemento de oposição, diante daquela "vontade criadora", modificando os resultados esperados. [...] é o responsável pela "dualidade" de Brasília, que tanto a aproxima das demais capitais latino-americanas (2012, p. 126).

Ademais, as fronteiras temporais, geográficas e sociais contidas e descritas na fábula de $B S P F$, se extrapoladas, podem ser reencontradas em níveis menos óbvios, mais amplos e entranhados no filme. Nesse sentido, BSPF é um filme de fronteira também por se tratar de um híbrido documentário + ficção científica, viabilizado a partir da reconfiguração e tensionamento de um esforço de produção a princípio focado em cinema documentário - daí nossa lembrança da estratégia do circuit bending, pois Adirley Queirós de fato "reconfigurou o circuito" com essa produção. Tomada essa situação em conjunto, BSPF pode ser lido como um metafilme a respeito do atual estado das políticas do audiovisual brasileiro, talvez ainda mais sofisticado e elaborado que Saneamento Básico, $O$ Filme (2007), de Jorge Furtado. Em sua estratégia narrativa distribuída ao longo de dois eixos, o documentário e o ficcional, BSPF contribui para outra tendência mundial no cinema de ficção científica contemporâneo: o recurso a um realismo de extração ou inspiração documentária que acentua o potencial de estranhamento diante de ficções especulativas, tal como podemos observar em filmes como Sob a Pele (Under the Skin, Jonathan Glazer, 2013), ou os já citados Sleep Dealer e Distrito 9. Todas essas produções recorreram à manipulação elaborada de técnicas documentárias, almejando resultados virtualmente impensáveis no terreno mais estrito da ficção.

Portanto, BSPF é representativo também, no Brasil, da recente retomada da tendência à combinatória entre ficção científica e documentário, configurando 
um regime de exposição no qual a situação fantástica favorece o estranhamento face ao mundo histórico. Especificamente no caso brasileiro, havemos de destacar, em filmes como BSPF e Barbosa, a aposta no tropos da viagem no tempo como "fórum de debates" acerca da "revisão" de "injustiças históricas". O filme de Queirós pode ser assim entendido como outra manifestação de "história alternativa", subgênero da prosa especulativa razoavelmente familiar a escritores brasileiros - como Gérson Lodi-Ribeiro, autor do conto "A Ética da Traição" (1993), aventura de espionagem ambientada num presente em que o Paraguai, vencedor da guerra contra a Tríplice Aliança no século XIX, seria hoje uma superpotência mundial, com território maior que o do Brasil que conhecemos.

Em resumo, a fronteira enquanto cenário, tema, estratégia ou simplesmente metáfora pode ser divisada em pelo menos três níveis do filme de Adirley Queirós: o diegético (os personagens transitando através de fronteiras temporais, geográficas e sociais), o formal (a narrativa transitando constantemente da ficção para o documentário, e vice-versa) e o institucional (o filme fronteiriço enquanto projeto, uma combinatória de documentário e ficção científica respondendo a um edital para cinema documentário).

A propósito, a fronteira enquanto metáfora parece uma constante ao longo de toda a obra de Adirley Queirós. Por exemplo, ao se referir a seu primeiro curta-metragem, Rap, o Canto da Ceilândia (2005), o diretor comenta que "[...] a questão do território é de fato deliberada: faço de caso pensado, porque para mim é identidade mesmo" (Reis, Mena e Imanishi, 2013, p. 3). Ainda segundo Queirós,

Para mim, o "canto" no título do filme [Rap, O Canto da Ceilândia] não era a música: "canto" era o território da Ceilândia. Era uma espécie de trocadilho: "canto" porque os caras são músicos, mas também no sentido de "beco", "quebrada". Por aí é que eu começo a enxergar e a formalizar a coisa. Acho que a história da cidade é muito forte e os filmes têm muito esse imaginário... (Reis, Mena e Imanishi, 2013, p. 29). 


\section{As fronteiras do corpo ${ }^{9}$}

Nas palavras do próprio Adirley Queirós, território é identidade, e assim seu cinema opera uma consequente justaposição entre corpo e território, fronteira e indivíduo.

Enquanto trans-border fantasy, no sentido de fábulas que especulam sobre o trânsito de personagens entre zonas interditas ou interditadas - a exemplo do já citado Sleep Dealer, ou ainda da própria série brasileira 3\%, concebida por Pedro Aguilera e dirigida por Daina Giannecchini, Dani Libardi e Jotagá Crema (https://www.youtube.com/ watch?v=R_rvS7nX7pM) - BSPF reinsere o multiculturalismo brasileiro na pauta não apenas do cinema, mas da ficção científica nacional (por mais tênue que sua interface com o gênero possa vir a ser). E com uma particularidade em relação a demais fábulas de fronteira: as geografias acidentadas e zonas de interdição não se restringem aos cenários ou paisagens por onde transitam os personagens; elas se inscrevem em seus próprios corpos, na mutilação que os limita ou interdita. "Índices" que intensificam o apelo documentário da ficção científica de Adirley Queirós, os corpos mutilados em BSPF são eles próprios "cartografias" da violência ou "mapas" da interdição, "geografias" alteradas pelo uso da força do estado. Esses corpos submetem-se a um duplo regime (o da ficção e o do documentário), à medida em que, por um lado, são legalmente impedidos de cruzar as fronteiras de Ceilândia e, por outro, não mais conseguem realizar as coreografias que costumavam apresentar no baile do Quarentão, devido às óbvias dificuldades de locomoção resultantes do confronto com os policiais. Se a movimentação da periferia para o centro é limitada ou proibida, agora até a dança, o movimento expressivo em seu próprio ambiente, é finalmente confiscado aos excluídos.

Na fábula de Adirley Queirós, a barreira geopolítica que exclui a periferia de Brasília do plano piloto deixa sua marca no corpo dos oprimidos: é mais difícil e trabalhoso locomover-se com a necessidade de próteses ou cadeira de rodas. O corpo, em BSPF, é uma geografia tão violentada quanto a do Planalto Central, ou de outros centros urbanos brasileiros. E as cenas de deslocamento de Marquim e Sartana, por mais "estranhadas" pela mise-en-scène que elas possam parecer (o elevador adaptado na casa de Marquim, a oficina de próteses onde trabalha Sartana), são também um retrato fiel de uma realidade nossa contemporânea e muito bem conhecida, porém sempre ocultada, interdita, ou

9 As considerações acerca do corpo em BSPF contaram com ideias originalmente trazidas a mim pela pesquisadora Paula Gomes, doutoranda sob minha orientação no Programa de Pós-graduação em Multimeios da UNICAMP. Todo este subtópico é fruto de nossa conversação a respeito da representação do corpo no filme de Adirley Queirós. 
referida de passagem: o fato de que o Brasil pune fisicamente seus excluídos, todos os dias, com acidentes de trabalho e/ou acidentes de percurso (no trajeto para o trabalho ou no trajeto para o lazer). Em outra ocasião, observamos que

Os corpos em BSPF remetem ao extra-filme da infra-estrutura de transporte público no Brasil, dos planos urbanísticos, das ruas e calçadas que bem conhecemos. Por que tão poucos deficientes físicos circulam pelas ruas brasileiras em comparação com países desenvolvidos? Porque, no Brasil, a rua [o espaço público] ainda não é lugar para o deficiente físico. $E$, diferentemente das bem conhecidas "narrativas de superação", BSPF não contemporiza. Os corpos mutilados não terminam por recuperar a dança, por criar novas coreografias com o recurso a cadeiras de rodas ou próteses. Sua expressão é contida. O desfecho é mesmo a explosão do centro irradiador da opressão - explosão esboçada em desenhos, numa vingança interditada ao cinema brasileiro live action (Suppia, 2015, p. 27).

\section{Lo-fi sci-fi: à guisa de conclusão}

As reiteradas referências ou metáforas relativas à música e sonoridade, ao canto e à voz (da periferia), afirmadas publicamente pelo diretor Adirley Queirós ou francamente identificáveis em $B S P F$, relacionam este filme ainda a outro horizonte de discussões: aquele do cinema de FC lo-fi (lo-fi sci-fi). Segundo definição do website <http://lofiscifi.com/>, o cinema de FC lo-fi compreende "[f]ilmes que têm mais especulação do que efeitos espetaculares. Mais focados em grandes idéias do que em grandes orçamentos"10.

BSPF pode ser reivindicado como representativo de um cinema brasileiro de FC Io-fi na medida em que, assim como demais títulos internacionais mencionados neste trabalho, apresenta-se como um filme de FC de orçamento modesto e extração realista, que prescinde de efeitos visuais sofisticados e que faz menção explícita a um "paradigma analógico", a um contexto low-tech de reapropriação e ressignificação dos resíduos industriais ou do lixo tecnológico, aludindo a um futuro igualmente low-tech e "ruidoso" em sua "programação visual". A exemplo de outros filmes comumente associados ao lo-fisci-fi-tais como Pi (Darren Aronofsky, 1998), Take Shelter (Jeff Nichols, 2011), Love (Will Eubank, 2011), Sound of my Voice (Zal Batmanglij, 2011), Another Earth (Mike Cahill, 2011),

$10 \quad$ No original: "Movies that have more speculation than spectacular effects. More focused on big ideas than big budgets". Todas as citações em língua estrangeira presentes neste artigo foram livremente traduzidas pelo autor. 
ou ainda Upstream Color (Shane Carruth, 2013) - BSPF opera uma "sensação de maravilhoso" (sense of wonder) baseada em desafios intelectuais que não raro dialogam de forma intrigante com o mundo histórico contemporâneo.

A reivindicação de $B S P F$ como filme brasileiro de FC lo-fi ganha destaque também na medida em que sua própria fábula tematiza o confronto entre baixa e alta cultura - lembremos da "bomba sonora" que destrói o plano piloto no desfecho do filme. Trata-se de uma arma low-fi num contexto de FC (aquele da viagem no tempo e da distopia de uma capital federal degradada pela sociedade do controle). Assim como o termo circuit bending, lo-fi sci-fi tem sua origem na arte e cultura sonoras. Lo-fi deriva de low fidelity, que em inglês significa baixa fidelidade. O termo teria sido cunhado pelo DJ William Berger, que nos anos 1980 tinha um programa na rádio WFMU em que dedicava parte do horário semanal a gravações caseiras. Na música, o lo-fi está relacionado tanto a gravações de baixo orçamento quanto a músicos que pretendem escapar ao mainstream da indústria fonográfica. Com origem na música, o termo lo-fi é hoje utilizado também como qualificativo aplicado a obras em fotografia ou vídeo, entre outros suportes. A voz da periferia, em BSPF, é lo-fi, assim como o tipo de FC com o qual o filme de Queirós dialoga.

Em resumo, a presente análise de BSPF pode sugerir alguns questionamentos de ordem mais ampla. Por exemplo, por que alguns dos mais celebrados filmes brasileiros de ficção científica alimentam-se da idéia de um personagem que regressa no tempo, com o objetivo de "corrigir" um fato passado? Esse tipo de narrativa poderia dizer mais acerca de nossa condição cultural? Jean-Claude Bernardet aponta alguns caminhos de reflexão sobre o assunto em seu ensaio "Cinema e Religião" (In: Xavier, 1996, p. 187-194), o qual abriga uma análise detida do curta Barbosa. A análise de Bernardet é particularmente interessante numa triangulação que envolva, além do filme de Jorge Furtado, o diagnóstico de Causo acerca da passividade dos personagens na ficção especulativa brasileira do século XIX, e finalmente o filme recente de Adirley Queirós. Porque já Barbosa acena com um possível "ponto fora da curva" no que se refere à passividade dos personagens. Em Barbosa, o viajante do tempo é um "empreendedor", ele de fato toma a iniciativa e se lança à difícil tarefa de mudar a história. Mesmo vindo a fracassar, sua iniciativa não é trivial, e representa um avanço no sentido de passar de um estágio de "desastre infligido" ao de "desastre provocado". Bernardet deixa isso mais claro:

O personagem [o viajante do tempo interpretado por Antônio Fagundes] vinha carregando a culpa dessa derrota que the tinha sido infligida aos onze anos. Com a operação na máquina do 
tempo, a derrota e a culpa continuam, mas algo essencial mudou: o personagem, pela sua ação, se responsabilizou pela derrota e assumiu a culpa. A vitória do personagem consiste exatamente nisto: a passagem da culpa infligida à culpa assumida. $O$ personagem deixou de ser objeto da culpa para se tornar sujeito (Bernardet, 1996, p. 194).

Diferente do apontado como habitual por Roberto de Sousa Causo na ficção especulativa brasileira do século XIX (Causo, 2003, p. 145), Barbosa oferece um viajante do tempo de fato, um agente genuíno. $E$ um personagem sintomático de uma eventual maturidade em seu enfrentamento da culpa assumida. Em BSPF não temos um viajante do tempo totalmente equivalente. Ele não busca transformar o passado exatamente, mas sim colaborar com uma utopia, um aperfeiçoamento futuro, em sua tarefa de coletar provas para a responsabilização do estado brasileiro. Por outro lado, os personagens correspondentes ao passado desse viajante do tempo (Marquim e Sartana, entre outros), estes sim assumem a agência, a missão de transformar a história por meio de seu ataque a Brasília.

O lo-fi sci-fi tem como característica o distanciamento de um cinema de FC mais modelar, e encontra em BSPF algumas soluções estéticas ou narrativas interessantes - tais como a exploração das locações em Ceilândia, ou o recurso às cartelas desenhadas por Shokito, no desfecho do filme - sinal da precariedade de um universo ficcional que contamina a forma de expressão. Lançar o apocalipse sobre Brasília, explodindo o congresso nacional, custaria caro no âmbito de um cinema de ficção científica modelar hollywoodiano (lembremos de Independence Day, de Roland Emmerich, 1996, entre muitos outros blockbusters), muito menos no âmbito do cinema digital independente (lembremos de Ataque de Pánico, de Fede Álvarez, 2009), e ainda muito, mas muito menos ao estilo Queirós/Shokito de cartelas desenhadas. E esta opção não deixa de ser eloquente por si mesma. A propósito, o desfecho de BSPF lembra outro filme brasileiro "de ficção científica", Projeto Pulex (Tadao Miaqui, 1991). Curioso notar que, enquanto em Projeto Pulex um plano governamental de extermínio da população periférica é posto em prática por meio da utilização de um inseto, a pulga, como vetor de doenças, em BSPF é a periferia que mobiliza uma estratégia de destruição do centro, por meio da utilização de música genuinamente popular, ou seja, artefatos culturais marginalizados pela parcela populacional mais privilegiada. Poderia ser visto aí um impulso mais ostensivo de iniciativa anti-establishment, tão tímido ou reticente nos anais da história brasileira, em nossa agenda contemporânea e mesmo em nossa produção ficcional? 
Dada sua repercussão entre a crítica e o público, BSPF talvez seja mais um evento do que meramente um filme, e sua visualização, desconectada de um contexto maior, parece nublar aspectos de sua própria trama. BSPF deixa uma marca no cinema brasileiro contemporâneo, com contribuições consequentes em termos de discurso e estilo. Conscientemente ou não, o filme de Queirós organiza em narrativa uma sensação de que o futuro não é nem será decidido em Brasília, mas na periferia do poder. A arma de destruição em massa a serviço do oprimido é a voz da periferia, encarnada por seus artistas mais genuinamente populares. A ação final, transformadora, não formula solução possível, e o filme termina com um "retorno do reprimido" e a reinstalação de uma situação de desequilíbrio - a capital está em ruínas e os sobreviventes do Quarentão foram vingados, mas e depois? Tal desfecho, francamente nihilista, parece operar no diapasão de um "grito" por justiça da parte das populações periféricas (negros e pobres). A "voz" é um elemento-chave em toda a filmografia de Adirley Queirós, um eventual estilema. $E$ a julgar pelo cenário político e econômico nacional dos anos que se seguiram ao lançamento de $\operatorname{BSPF}$ (2015 e 2016), não surpreende que o filme de Queirós não ofereça saída senão pela via do "grito", da busca violenta por reparação. Num país de frágil tradição democrática, a violência perpetrada pelo estado nunca é de fato reparada, e sempre deixa como herança estigmas nos corpos de suas vítimas. Se, por um lado, filmes de discurso virtualmente conservador projetam o modernismo de Brasília em cidades fictícias de caráter utópico e idealizado (como Nosso Lar), BSPF oferece uma ficção especulativa materialista sobre o futuro da capital federal enquanto metonímia do país. Em comunicação apresentada ao Colóquio sobre as Capitais da América Latina, realizado na Universidade de Tolouse em fevereiro de 1964, Milton Santos observou que "[v]ontade criadora e subdesenvolvimento do país são, pois, os termos que se afrontam na realização efetiva de Brasília. É da sua confrontação que a cidade retira os elementos de sua definição atual" (Santos, 2012, p. 126). Gostaríamos de transportar o mesmo diagnóstico ao filme de Adirley Queirós, uma obra cujo élan vital se consubstancia exatamente nessa confrontação entre "vontade criadora" e "subdesenvolvimento", manifesta na distopia de BSPF, seus personagens, cenários e mise-en-scène, do primeiro plano ao desfecho "impuro" narrado por meio de cartelas desenhadas. Sério candidato a filme cult no panorama do cinema brasileiro contemporâneo, BSPF oferece uma leitura cinematográfica "sobre o fio da navalha" dos muitos brasis que já ousamos perscrutar. 


\section{Referências:}

BERNARDET, Jean-Claude. Cinema e Religião. In: XAVIER, Ismail (org.). O Cinema no Século. Rio de Janeiro: Imago, p. 187-194, 1996.

BERGAMASCHI, Mara. Brasília Estranha. In: CATALDO, Beth; RAMOS, Graça. Brasília aos 50 Anos - Que Cidade é Essa? Brasília:Tema Editorial, p. 23-34, 2010.

CANDIDO, Antonio. Literatura e Sociedade. São Paulo: PubliFolha, 2000.

CAUSO, Roberto de Sousa. Tupinipunk - Cyberpunk Brasileiro. Papêra Uirandê Especial \# 1: Tupinipunk. São Paulo: edição do autor, p. 5-11, 1996.

Ficção Científica, Fantasia e Horror no Brasil - 1875 a 1950. Belo Horizonte: Ed. UFMG, 2003.

O estado da arte: ficção científica tupinipunk. Papêra Uirandê Especial \# 9: Tupinipunk no Século XXI. São Paulo: edição do autor, p. 11-14, 2015.

LIM, Dennis. At the Border Between Politics and Thrills. The New York Times. 15 mar. 2009. Disponível em: <http://www.nytimes.com/2009/03/15/movies/15denn. html >. Acesso em: 18 mai. 2016.

LISPECTOR, Clarice. Nos Primeiros Começos de Brasília. In: XAVIER, Alberto; KATINSKY, Julio (orgs.). Brasília - Antologia Crítica. São Paulo: Cosac Naify, p. 179-182, 2012.

LODI-RIBEIRO, Gerson. A Ética da Traição. In: MORAIS, José Manuel (org.). O Atlântico tem Duas Margens. Lisboa: Editorial Caminho, p. 81-112, 1993.

MORAVIA, Alberto. Brasília Barroca. In: XAVIER, Alberto; KATINSKY, Julio (orgs.). Brasília - Antologia Crítica. São Paulo: Cosac Naify, p. 90-94, 2012.

PEDROSA, Mário. Reflexões em Torno da Nova Capital. In: XAVIER, Alberto; KATINSKY, Julio (orgs.). Brasília - Antologia Crítica. São Paulo: Cosac Naify, p. 33- 43, 2012.

REIS, Cláudio; MENA, Maurício Campos; IMANISHI, Raquel. Entrevista com Adirley Queirós. Negativo, v. 1, n. 1, p. 16-70, set. 2013.

RIVERA, Lysa. Future Histories and Cyborg Labor: Reading Borderlands Science Fiction after NAFTA. Science Fiction Studies, v. 39, n. 3, Science Fiction and Globalization, p. 415-436, nov. 2012.

SANTOS, Milton. Brasília e o Subdesenvolvimento Brasileiro. In: XAVIER, Alberto; KATINSKY, Julio (orgs.). Brasília - Antologia Crítica. São Paulo: Cosac Naify, p. 125-135, 2012.

SNYDER, David E. Outras Perspectivas sobre Brasília. In: XAVIER, Alberto; KATINSKY, Julio (orgs.). Brasília - Antologia Crítica. São Paulo: Cosac Naify, p. 121-124, 2012. 
SUPPIA, Alfredo. Entrevista com Adirley Queirós e Maurílio Martins. Brasília, 12 jun. 2015. Disponível em: <https://youtu.be/7t64uDP2rPo >. Acesso em: 14 fev. 2016.

SUPPIA, Alfredo; GOMES, Paula. Por um cinema infiltrado: entrevista com Adirley Queirós e Maurílio Martins a propósito de Branco Sai, Preto Fica (2014). Doc OnLine, n. 18, Interatividade e documentário, setembro de 2015. Disponível em: $<$ http://www.doc.ubi.pt/18/entrevista 2.pdf >. Acesso em: 14 fev. 2016.

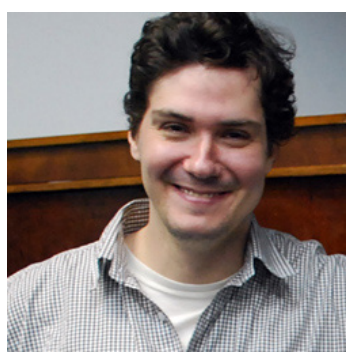

Recebido em: 18/6/2016

Aprovado em: 6/7/2016

Endereço do autor:

Alfredo Suppia <alsuppia@iar.unicamp.br>

Programa de pós-graduação em Multimeios, Universidade Estadual de Campinas (Unicamp)

Rua Elis Regina, 50 - Cidade Universitária "Zeferino Vaz" - Bairro São Geraldo

13083-854 - Campinas - SP - Brasil 